\title{
The Applicability of Artificial Intelligence in International Law
}

\section{Young-Yik Rhim* \& KyungBae Park**}

Law reacts to the progression of scientific technology in the end. Though conservative, changes are beginning to take place due to Artificial Intelligence (AI). AI is automating conventional legal works, creating a new industry namely Legal-Tech. This paper investigates the characteristics and flow of legal-AI and computational law while focusing on the applicability of AI to international law. Mainly, the paper reviews three critical areas: dispute resolution, trial prediction, and machine translation, respectively. International law has different characteristics than the domestic law applied in each country. Unlike domestic law, international law has not been aggregated from a pandect, and it is a still daunting task to draw any meaningful insights for further analysis due mainly to limited data (i.e., trial cases and precedents). Nevertheless, AI is already penetrating the legal ecology system, and international law would eventually accept the influx of such changes exhibiting greater force.

\section{Keywords}

International Law, Artificial Intelligence, Machine Learning, Deep Learning, Computational Law, Legal-Tech, ODR, Trial Prediction, Machine translation

* The first and corresponding author. Representative Lawyer and CEO of Intellicon Metalab; Adjunct Professor of Mass Communication and Public Relation at Konkuk University (Seoul, Korea); Member and Judge of ICAIL; Vice President of Korean Association for Artificial Intelligence and Law. ORCID: https://orcid.org/0000-0001-9252-4159. The author may be contacted at: ceo@intellicon.co.kr/Address: 554, Nonhyeon-ro, Gangnam-gu, Seoul 06136 Korea.

** The second author. Researcher at Intellicon Metalab. Ph.D.(Kyungbook N.U.) The author may be contacted at: kbp@ intellicon.co.kr 


\section{Introduction}

Machine learning and deep learning are the symbols of modern Artificial Intelligence ("AI"). They have become familiar to us after AlphaGo. However, its history dates back to a very long time. The origin of Machine learning can be found in Artificial Neural Network (“ANN") which emulates the human- neural networks. McCulloch and Pitts (1943) ${ }^{1}$ proposed the first mathematical model of the ANN. Using the McCulloch-Pitts model, Frank Rosenblatt (1957) ${ }^{2}$ invented the ANN-Algorithm ('Perceptron'). ANN and Perceptron created the concept of Machine Learning which is a methodology that is completely different from the Rule-based AI. Machine learning is an application of AI that provides computer the ability to automatically learn from data without being explicitly programmed. AI methodology is largely classified into Rule-based and Learning-based (Machine learning). These two methodologies have advantages and disadvantages, respectively.

In Machine Learning, there are various models ${ }^{3}$ other than ANN, but ANN is the representative algorithm. ANN created a concept called Machine Learning and gained attention for a long period. However, ANN could not develop significantly due to technical issues such as overfitting and lack of data and gradually collapsed after the 1990s. In the year 2000, the chronic issues of the neural network were resolved one by one by Geoffrey Hinton and others. In 2006, Geoffrey Hinton team published a monumental paper ${ }^{4}$ with the support of Canada. This paper revealed that the chronic issues of the ANN could be resolved through pre-training of data and marked a new milestone in the research on ANN. After this paper, the word, 'Deep learning' started to gain popularity. In 2012, ${ }^{5}$ the Hinton team won with overwhelming performance at the "ImageNet Large Scale Visual Recognition Competition ("ILSVRC")," an image recognition competition. In 2016, AlphoGo made an appearance. Today, the era of AI based on deep learning was opening its doors again. AI is now transforming all industries and economic structures. Global IT companies such as Google, Facebook, Microsoft and Amazon have all announced

1 W. McCulloch \& W. Pitts, A Logical Calculus of the Ideas Immanent in Nervous Activity, 5 Bull. Math. Biophysics 115-33 (1943).

2 F. Rosenblatt, The Perceptron, A Perceiving and Recognizing Automaton Project Para 1-29 (Cornell Aeronautical Laboratory ed., 1957).

3 For example, Regression, Decision Tree, Naive Bayes, Support Vector Machine, etc.

4 G. Hinton, et al., A Fast Learning Algorithm for Deep Belief Nets, 18 Neural Computation 1527-54 (2006).

5 A. Krizhevsky, et al., Imagenet Classification with Deep Convolutional Neural Networks, 25(2) AdvanCES IN NEURAL. InFormation Processing Systems 1097-105 (2012). 
that the core technology of the future is AI and are investing significant amount of money. AI is equivalent to the surviving technology of a nation and corporate.

However, law reacts last to the progression of scientific technology in the end. Even in such a conservative world of law, things are fast changing due to AI. Actually, AI and computers began to transform the conventional legal works. $\mathrm{AI}$ and Legal Tech have created a new legal industry. Legal searching tools like Ross Intelligence $^{6}$ are equipped with voice recognition and propose accurate legal materials with regards to such questions. AI continuously creates new services such as intelligent search, contract analysis, trial prediction and document automation.

This research deals with the characteristics and flow of legal AI and computational law while focusing on how the AI technology would apply to international law. This paper is composed of four parts, including Introduction and Conclusion. Part two will discuss Legal AI and Legal Tech. Part three will tackle highly topical questions on international law and AI.

\section{Legal AI and Legal Tech}

\section{A. Artificial Intelligence and Expert System}

The captivating terminology of AI was first used in the 1956 Dartmouth Conference and is widely known throughout the world. The historical Dartmouth Conference was participated by the geniuses of the time such as John McCarthy, Marvin Minsky and Herbert Simon. There were various discussions on computer theory, machine intelligence and natural language processing. After the Dartmouth Conference, a methodology called 'Symbolic AI' thrives significantly. ${ }^{7}$

With the 1956 Dartmouth Conference as a start, scholars predicted that AI similar to that of humans could be realized. However, contrary to the initial expectation, it was soon revealed that AI did not easily solve the complex problems or real-world issues. This evidenced the fundamental limitations of Symbolic AI. As such, AI collapsed in vain and the first AI winter began in early in 1970s.

The first AI era, referred to as the era of reasoning and search, let down the curtain

ROSS Intelligence is a legal searching service that harnesses the power of AI to make legal research more insightful.

7 Symbolic approach refers to the research technique based on formal logic and symbol system in the field of inference, search, problem-solving and others. In plain language, it is an approach method that aims to solve the problems of the world through symbols and rules, just like mathematics. 
and the methodology of using 'knowledge' itself developed. In the 1970s, the second AI boom unfolded. During this period, 'Expert System' equipped with knowledge comparable to that of a human expert became greatly popular. An Expert System is a program that answers questions or solves problems about a specific domain of knowledge, using logic and rules that are derived from the knowledge of human experts. ${ }^{8}$ In order to develop an Expert System, human experts have to reorganize specific professional knowledge represent it as logic and rules (if-then rules). An expert system can be divided into two subsystems: the inference engine and the knowledge base. The knowledge base represents facts and rules. The inference engine applies the rules to the known facts to deduce new facts.

The world's first Expert System, 'DENDRAL' was introduced at the end of the 1960s. ${ }^{10}$ DENDRAL is capable of inferring the types of organic chemicals with a mass spectrum data of chemical substances and can be referred to as a sort of 'AI-Chemist."11 Since the advent of DENDRAL, the Expert System which infers by expressing knowledge in specific area in a rule prospered significantly. For example, 'MYCIN' is the world's first medical expert system developed in 1970s by Bruce Buchanan of Stanford University, the US. ${ }^{12}$ This system diagnoses contagious blood diseases and prescribes appropriate antibiotics. Here, the related medical knowledge is expressed in over 600 rules.

\section{B. Legal Expert System}

With the success of the medical expert system, there arose a movement to apply the expert system in another specialist area, namely 'the law.' In 1970, a paper on the technique of applying the expert system in law was published. ${ }^{13}$ This paper

8 Shu-Hsien Liao, Expert System Methodologies and Applications-A Decade Review from 1995 to 2004, 28 EXPERT Systems with Applications 93-103 (2005).

9 Bo K. Wong \& J. Monaco, Expert System Applications in Business: A Review and Analysis of the Literature (19771993), 29 Info. \& MGMt. 141-52 (1995).

10 J. Lederberg, A System for Computer Construction, Enumeration and Notation of Organic Molecules as Tree Structures and Cyclic Graphs (technical reports to NASA); See also the author's summary [12]; (1a) pt. I. Notational Algorithm for Tree Structures (1964), CR.57029; (1b) Part II. Topology of Cyclic Graphs (1965), CR.68898; (1c) pt. III. Complete Chemical Graphs; Embedding Rings in Trees (1969).

11 Id.

12 E. Shortliffe., MYCIN: A Rule-Based Computer Program for Advising Physicians Regarding Antimicrobial Therapy Selection (1974) (Unpublished PhD thesis, Stanford University). See also E. Shortliffe et al., Computer-Based Consultations in Clinical Therapeutics: Explanation and Rule Acquisition Capabilities of the MYCIN System, 8 Computers \& Biomedical Res. 303-20 (1975).

13 B. Buchanan \& T. Headrick, Some Speculation about Artificial Intelligence and Legal Reasoning, 23 STAN. L. REV. (1970). 
discussed how computer science would be applied in the work of attorneys and legal argumentation. In particular, this paper concluded that the physical, financial and technical issues should be resolved in order to complete the legal expert system in detail. ${ }^{14}$ Since then, there has been continuous interest and research on AI and legal reasoning. In 1977, Thorne McCarty developed the first legal expert system called 'TAXMAN.' 15 This system materialized the algorithm which expressed the rule and concept of the Federal Tax Law in the US. ${ }^{16}$ The TAXMAN project was an extremely experimental attempt but exhibited good performance in legal reasoning. Afterwards, Kevin Ashley begins to develop a Case-based System, imitating the inference process of human attorney. ${ }^{17}$ Ashley completed the world's first Case-based System called, 'HYPO' in 1987. ${ }^{18}$ After Ashley's methodology, many legal expert systems were created. It was followed by 'CHIRON' $(1991)^{19}$ for the tax law in the US, 'LOGEEXPERT' (1991) ${ }^{20}$ for National Housing Act in Quebec, Canada and others.

In particular, the 'SHYSTER'(1993) ${ }^{21}$ system, as an inference system for the field of intellectual property, developed by James Popple in Australia has been evaluated as the most successful model out of the Case-based system. Popple also presented a hybrid expert system called 'SHYSTER-MYCIN'(2003) ${ }^{22}$ by combining the Case-based SHYSTER and Rule-based medical system MYCIN. In spite of many researches after then, we have hardly seen an AI lawyer of an expert system. This is because the legal expert system did not exhibit the performance that was expected in reality. It did not just apply to law, but was also the same case in the expert systems in other fields.

In an expert system, basically, humans have to represent or combine all rules from outside. However, such a process is bound to require unlimited time and cost.

14 Id.

15 L. T. McCarty, Reflections on TAXMAN: An Experiment in Artificial Intelligence and Legal Reasoning, 90 HaRv. L. REV. 837-93 (1977).

16 It enables users to execute the work such as calculating the corporate tax with regards to capital transactions through computer programs by saving the details of law related to corporate tax in US as algorithm in the computer program.

17 Case-based System began from a research by Roger Schank from Yale University in the beginning of 1980 s. It is the representative expert system methodology along with Rule-Based.

18 E. Rissland \& K. Ashley, A Case-Based System for Trade Secrets Law, 60-6 (ACM 1987) available at http:// citeseerx.ist.psu.edu/viewdoc/download?doi=10.1.1.91.3298\&rep=rep1\&type=pdf (last visited on May 30, 2019).

19 K. Sanders, Representing and Reasoning about Open-Textured Predicates (ACM 1991), available at http://egov.ufsc. br/portal/sites/default/files/anexos/2713-2707-1-PB.pdf (last visited on May 30, 2019).

20 L.-C. Paquin, et al., LOGE-EXPERT: From A Legal Expert System to an Information System for Non-Lawyers (ACM 1991), available at https://dl.acm.org/citation.cfm?id=112678 (last visited on May 31, 2019).

21 J. Popple, SHYSTER: A Pragmatic Legal Expert System (1993) (unpublished Ph.D. thesis, Australian National University).

22 T. A. O'callaghan, et al., SHYSTER-MYCIN: A Hybrid Legal Expert System (ACM 2003), available at http://users.cecs. anu.edu.au/ Eric.McCreath/papers/icail-03.pdf(last visited on May 30, 2019). 
Especially when new knowledge has to be added or a rule has to be changed, it is extremely difficult to reflect it automatically. In the end, as critical disadvantages such as development cost and maladjustment to circumstances were revealed continuously, the popularity dropped. This was the second winter of AI in the 1990s.

In today's deep learning, the word 'expert system' is not widely used. However, the majority of AI is still created in the form of the classical expert system. Various expert systems such as Diagnosis System, Planning System, Configuration System, Decision Support System, Advising System and Monitoring System exist. ${ }^{23}$

\section{Computational Law}

The legal expert system studied previously was significant in the history of legal AI. It is because computer was able to make legal reasoning by using legal knowledge. However, the concept and attempt on using law and computer science existed before the advent of the Expert System. The theoretic methodology of using computer in law is called 'Computational Law.' ${ }^{24}$ This terminology is used together with Legal Informatics, Legal AI, Jurimetrics, etc. Computational Law was named from the perspective of reasoning and algorithm but it is also called 'Legal Informatics' from the perspective of data analysis process or informatics. ${ }^{25}$

At first glance, AI and law look entirely different. In terms of inference structure or methodology for problem solving, however, there are quite several common elements. ${ }^{26}$ In fact, in the legal area, the law itself is described in the form of rule and logic. Moreover, AI shares similar structure in terms of taking after logical representations. Due to such similarities, the possibility of utilizing AI in the field of law began relatively earlier in the UK, the US or the EU.

As soon as the name AI appeared in the Dartmouth Conference, a surprising paper on computation method which converts law in formal logic was published by Layman Allen. ${ }^{27}$ Converting law into formal logic means that legal knowledge

23 E. Thiessen, et al., ODR and enegotiation, in Online Dispute Resolution: Theory and Practice: A Treatise on Technology and Dispute Resolution (M. Wahab et al. eds., 2012).

24 N. Love \& M. Genesereth, Computational Law (ACM 2005), available at http://logic.stanford.edu/publications/love/ computationallaw.pdf (last visited on May 30, 2019).

25 Legal informatics is considered as a super ordinate concept of the science of law but after Machine Learning-Based AI technology has been applied, there is no significance in categorizing these two. However, in case of biology, Bioinformatics and Computational Biology are used differently.

26 D. Carneiro et al., Conflict Resolution and its Context from the Analysis of Behavioral Patterns to Efficient DECISION-MAKING 63 (2014).

27 L. Allen, Symbolic Logic: A Razor-Edged Tool for Drafting and Interpreting Legal Documents, 66 YALE L. J. 833-79 (1957). 
is converted for computers to process. Therefore, Allen's research in fact provided mathematical structure and methodology for the realization of legal AI for the first time and it could be considered as a start of Computational Law.

However, when the AI Revolution was reaching Europe from the US, a detailed and practical methodology with regards to legal AI was proposed. ${ }^{28}$ Lucien Mehl claimed that legal work had to be automated by actively introducing computational methodology to law. He classified the legal automation methodology using computer into two types: a searching engine which would provide the legal researcher with both quick access to relevant case precedents and legal scholarship, and a question and answering (Q\&A) system which would enable legal counseling. ${ }^{29}$ He predicted that if computers were actually applied to law based on these two concepts, the majority of the lawyer's work could be automated and the future legal service would be innovated. ${ }^{30}$

Thanks to innovators like Layman Allen and Lucien Mehl, law was finally able to encounter 'computationalism' relatively faster than other studies. The computation of law refers to the technique which formalizes legal structure and logic so that an automation algorithm or machine could execute legal reasoning. Computational Law, which started together with the history of AI was materialized in detail in the form of an Expert System. Computational law which accompanied rise and fall of 'AI.' It was combined with the AI technology such as Machine Learning, Deep Learning, Natural Language Processing for a significant advancement and positioned itself into another field of study. ${ }^{31}$ Currently, official lecture of AI is established in renowned US law schools. Based on such study, legal AI and the Legal Tech industry are keep developing in a virtuous cycle.

\section{Legal Tech}

Legal AI is a terminology that includes legal expert system and Computational Law which is a theoretical study. Legal AI can be examined in detail in an industry called 'Legal Tech.' Legal Tech is a compound word of "Legal + Technology." The most

30 Id.

31 In 1987, International Conference on Artificial Intelligence and Law (ICAIL) was introduced. Through this international conference, scholars exchanged various information and computational law was disseminated not only in US but also around the world. 
famous case in Legal Tech is 'Ross Intelligence. ${ }^{, 32}$ With a natural language processingbased legal search engine, Ross was developed using the IBM Watson API. On the other hand, 'DoNotPay' was introduced to the world of legal AI under the title, "World's first robot lawyer"; it is a sort of legal Q\&A ChatBot that offers legal advices with regards to parking violations. ${ }^{33}$ In addition, 'LISA' provides document automation service under the promotional phrase of 'Robot lawyer.' Whether convenience or not, the three abovementioned systems became known to the world in 2016 when AlphaGo appeared.

Legal technology traditionally referred to the application of technology and software to help law firms with practice management, Legal technology traditionally referred to the application of technology and software to help law firms with practice management, document storage, billing, accounting, and e-discovery. ${ }^{34}$ The types of Legal Tech industry are as diverse as the work of lawyers. In the end, all the services with the nickname of AI lawyer can be considered as one of Legal Techs. ${ }^{35}$

In fact, the root of Legal Tech is extremely deep. The encounter of computer and law itself is the beginning of Legal Tech; it visually appeared in the form of legal search service. After the 1950s, computer positioned itself as an essential tool for searching for documents or materials. In the legal area, as searching for precedents or legal documents is extremely important, computer was applied earlier than other fields. In 1960s, the Ohio Lawyer Association in the US already introduced the computer system to search for precedents. ${ }^{36}$ Since then, legal search service unfolded in a full scale in the private sector. 'LexisNexis' started the legal search service for the first time in the private sector and 'Westlaw' joined the search service business based on massive database of legal documents. With these two companies almost dominating the legal search service, Legal Tech was not able to secure diversity in the industry of itself. ${ }^{37}$

32 M. Addady, Meet Ross, the World's First Robot Lawyer, Fortune, May 12, 2016, available at http://fortune.com/ 2016/05/12/robot-lawyer (last visited on May 14, 2019).

33 J. Porter, Robot lawyer DoNotPay now Lets You 'Sue Anyone' Via an App, Verge, Oct. 10, 2018, available at https:// www.theverge.com/2018/10/10/17959874/donotpay-do-not-pay-robot-lawyer-ios-app-joshua-browder (last visited on May 14, 2019).

34 E. Hibnick, What is Legal Tech?, LAw Insider, Sept. 7, 2014, available at https://www.thelawinsider.com/insidernews/what-is-legal-tech (last visited on May 1,2015).

35 P. Gunst, The Legal Tech Startup Landscape: CODEX FUTURE LAW 2018, Stanford University Website, available at https://conferences.law.stanford.edu/futurelaw/wp-content/uploads/sites/48/2018/03/FutureLaw2018.pdf (last visited on May 12, 2019).

36 F. Troy, Ohio Bar Automated Research-A Practical System of Computerized Legal Research, 10 JuRIMETRICs J. 62-9 (1969).

37 LAC Group, LexisNexis versus Westlaw revisited, LAC Group Website (Feb. 22, 2018), available at https:/lac-group. com/lexisnexis-versus-westlaw-revisited (last visited on May 11, 2019). 
In 2001, an online law firm called 'LegalZoom' began providing various legal services, it started to improve the problems of offline services and gain attention. The existing lawyers in the industry filed a lawsuit against LegalZoom for violation of the Attorney Law, ${ }^{38}$ but the court took the side of LegalZoom. Since then, LegalZoom has continued to apply new technologies in order to improvise the problems of online services. Now, it has become a brand that is more famous than large-scale law firms by securing millions of customers. ${ }^{39}$

In the US, the Discovery system developed and based in ICT technology, and the automation industry of legal documents advanced early. In particular, in e-Discovery, a lot of legal cost is incurred from the work of analyzing massive amount of digital documents. John Kelly established the 'BlackStone Discovery' in 2003. ${ }^{40}$ This company is capable of analyzing documents of 1.5 million cases at 10 percent of the human lawyer cost.

In 2009, 'Lex Machina' which is a Legal Tech company that applies statistics prediction technology to law appeared. Lex Machina, which started as a joint project by Stanford University's Law School and the Department of Computer Engineering, provides statistics information by analyzing the US Federal Court's Docket related to litigation and various litigation materials as well as various visual prediction materials. $^{41}$

Legal Tech was able to root itself early in the US due to reasons such as high legal costs and e-discovery system. However, the explosive growth of Legal Tech is deeply related to the resurrection of AI. Machine Learning technology such as deep learning opened a new era of AI and affected all the industries. and Legal Tech field was not an exception, too. When Machine Learning technology and natural language processing technology penetrated law, completely different legal systems that were from the previous became possible. As it can be seen from the advent of Ross, Legal Tech is becoming more intelligent with its application in simple automated legal service and furthermore in AI technology. By witnessing the rapid emergence of Legal Tech industry, it helps understand how legal AI has been developed.

38 Lawyers in the US claimed that LegalZoom which uses science technology to provide legal counseling to customers was "Unauthorized Practice of Law."

39 See The Global Unicorn Club, CB Insights (Jan. 2019), available at https://www.cbinsights.com/research-unicorncompanies (last visited on May 8, 2019).

40 See Company Overview of Blackstone Discovery Inc., BloOMBerg, May 17, 2019, available at https://www.bloomberg. $\mathrm{com} / \mathrm{research} /$ stocks/private/snapshot.asp?privcapid=62452908 (last visited on May 17, 2019).

41 Lex Machina was taken over by an American legal information company, 'LexisNexis' and is evaluated as the representative successful model of LegalTech. 


\section{International Law and Artificial Intelligence}

\section{A. Dispute Resolution and Artificial Intelligence}

In the legal field, because AI can be utilized in the overall dispute resolution procedure, automation technology can easily be applied as Alternative Dispute Resolution ("ADR") instead of litigation in court. In particular, there is a high possibility of applying the AI technology in Online Dispute Resolution ("ODR"). Furthermore, AI can also be applied in arbitration or mediation. The ICT technology and AI which lay the foundation for ODR can be applied in international arbitration and other dispute settlement mechanism.

The arbitration procedure is a sort of private trial for resolving dispute in accordance with the procedure that has been agreed by both parties in advance. It usually involves the parties concerned appointing a lawyer, legal professor or other specialists as an arbitrator to resolve the disputes when a 1-person or 3-person arbitrators conduct a hearing, reach a verdict, and assign legal binding force in the court judgment. ${ }^{42}$ Such arbitration system is widely utilized in businesses or international transactions such as construction fields where standardized disputes often occur. The key to arbitration procedure lies in the parties concerned reaching an agreement autonomously on the dispute resolution method so that the parties concerned can utilize AI by reaching an agreement in order to reduce dispute resolution expenses and time.

\section{ODR and Al}

The ODR is an effective method of resolving dispute with regards to massive quantity of e-Commerce. The United Nations Commissions on International Trade Law ("UNCITRAL") recognizes that the dispute resolution method under the conventional legal system is unable to provide appropriate or efficient resolution for e-Commerce disputes between countries. Therefore, as an alternative, it endeavors to establish an international ODR system for massive dispute that is small in terms of amount. ${ }^{43}$ The UNCITRAL established an ODR platform to handle disputes in international e-Commerce and commenced its operation. First, the operation of platform started

42 J. Murray, Learn How the Arbitration Process Works, Bus. L. \& Tex., Feb. 13, 2019, available at https://www. thebalancesmb.com/what-is-the-arbitration-process-how-does-arbitration-work-397420 (last visited on May 8, 2019).

43 G.A. Res. 65/17, U.N. Doc. A/65/17 (June 21-July 9, 2010), available at http://www.uncitral.org/uncitral/en/ commission/sessions/43rd.html (last visited on May 30, 2019). 
for ADR institute (Jan. 9, 2016) and then, the operation commenced for consumers and businessmen (Feb. 15, 2016). National Arbitration Forum (NAF), Asian Domain Name Dispute Resolution Centre (ADNDRC) and American Arbitration Association (AAA) in which the authority for resolving disputes related to domain name (online) has been approved by the Internet Corporation for Assigned Names and Numbers (ICANN) provides official ODR, as well. ${ }^{44}$ Moreover, there are commercial ODR providers such as Modria, Cybersettle and SmartSettle that offer online dispute resolution as their businesses. Amazon or eBay provides in-house ODR services, respectively. ${ }^{45}$

The possible AI in ODR is a conventional expert system like the Decision Support System. Also, the Negotiation Support System, Auto Counseling System and others are widely used in practice. In the case of the Decision Support System, it was utilized in the field of Product Liability Act in 1980. At the time, the Rule-based Legal Decision-Making Systems ("LDS") developed by Rand ${ }^{46}$ was used by legal experts to resolve problems in the litigation case of product liability. ${ }^{47}$

In the case of the Negotiation Support System based on the Decision Support System, extremely diverse programs have been developed and utilized such as Adjusted Winner, AniMed, AutoMed, Cybersettle, AssetDivider, Fair Outcomes, and Smartsettle. Among them, 'Smartsettle' of iCan Systems Inc. has been used relatively comprehensively. Smartsettle is an arbitration program with optimized algorithm, offering maximum profit to all parties concerned in the negotiation. ${ }^{48}$ Smartsettle can be utilized in small-sum claim, insurance and settlement of loan, family, company, regional community, government, development of water resources and a treaty on international peace. The advantage of Smartsettle is that it enables online negotiation, so that more efficient result can be obtained than face to face meetings and that prompt and fair agreement can be identified through early intervention. In addition, when the parties concerned in dispute are unable to meet due to different schedule, negotiation can be done asynchronously, and multiple sessions of negotiation process can be constituted. Generally, it can be thus executed faster than the general

\footnotetext{
44 Kangwon Joo, A Study on the Use of the Artificial Intelligence and its Legal Meaning in the Process of Online Dispute Resolution, 17 HongIK L. Rev. 81-103 (2016). <available only in Korean>

46 In the early 1980s, Rand was a company that advised on risk assessment in damage case. The system was to investigate the effect of changes in legal doctrine on settlement strategies and practices.

47 D. Waterman \& M. Peterson, Rule-Based Models of Legal Expertise (1980), available at http://new.aaai.org/Papers/ AAAI/1980/AAAI80-077.pdf (last visited on May 1, 2019).

48 iCan Systems Inc., Beyond Win-Win, Smartsettle Homepage, available at https://smartsettle.com (last visited on Mar. 15, 2019).
} 
arbitration process. $^{49}$

The most successful system among many private ODR systems is the eBay Resolution Center. ${ }^{50}$ Presently, the Center handles more than 60 million cases in a year and a significant part is operated with an automated system. The eBay Resolution Center has been so designed that the parties concerned can exchange opinions and reach an agreement by themselves through a platform. ${ }^{51}$

The automated counseling system is not very different from the Decision Support System considering that it is utilized in online dispute resolution. One of the most recent automated counseling systems that is utilized in online dispute resolution is the 'Solution Explorer' provided pursuant to the Civil Resolution Tribunal Act in British Columbia, Canada. ${ }^{52}$ Solution Explorer started its beta test in January 2016 and provides automated counseling service on cases related to collective building with a program that is currently undergoing multiple tests. ${ }^{53}$ It provides information on the progress of problem resolution by analyzing the disputes based on the information inserted or selected by the disputing party and offering detailed information for its resolution prior to proceeding with the actual negotiation or conciliation. ${ }^{54}$

\section{International Arbitration and Al}

The Expert System technology or AI technology that has appeared in ODR can be applied to international arbitration, as well. ${ }^{55}$ Considering the characteristics of international arbitration, the following scenarios can be possible.

First is the selection of arbitrator, which is one of the most important procedures in arbitration. Parties often ask what factors to consider and how to find information that may assist them in assessing a candidate for nomination to a Tribunal. The AI can be useful in this process. Above all, AI prepares the arbitrator's profile through database or Internet and then analyzes the detailed information of the arbitrator. Next, it selects the appropriate arbitrator for the relevant dispute and ranks them. AI can judge the conflicting interests between the parties concerned and can recommend three optimal arbitrators in the end. Such a system could be based on Expert System

Do Hoon Kim, A Study on the Use of Artificial Intelligence on the Online Dispute Resolution, 17 HongIK L. REv. 63-92 (2016). < available only in Korean>

50 eBay, Resolution Center, available at https://resolutioncenter.ebay.com (last visited on Mar. 17, 2019).

51 C. Rule \& V. Rogers, Building A Global System for Resolving High-Volume, Low-Value Cases, 29 Alternatives to the High Cost of Litigation 135-6 (2011).

52 Solution Explorer, Civil Resolution Tribunal, available at https://civilresolutionbc.ca (last visited on Mar. 21, 2019).

53 Id.

54 Kim, supra note 49.

55 C. Sim, Will Artificial Intelligence Take over Arbitration?, 14 Asian InT’L ARB. J. 1-14 (2018). 
or could be applied with data analytics. ${ }^{56}$

Second, AI can play the role of an arbitrator. According to the "UNCITRAL Model Law" ${ }^{\prime 57}$ which is an assisting institution of the UN that enacts the International Trade and Commercial Law, arbitration using AI is not impossible. In the $1958 \mathrm{New}$ York Convention, ${ }^{58}$ there is no expression that the arbitrator must be a human. The arbitration by AI can be thus acknowledged. ${ }^{59}$

However, for the AI to act as a human arbitrator, a few risks exist. For example, an algorithm bias ${ }^{60}$ such as 'gender' 'age' and 'race' may exist in the AI system itself, so that there may be a risk of reaching a conclusion preferable to a conglomerate or specific country in the process of arbitration. Also, the measures to guarantee the 'due process' of arbitration and 'transparency' of arbitration decision are currently uncertain. As a result, it is difficult for AI to replace human arbitrators in international disputes in terms of social and political context. Therefore, as of today, automated system would be the measure in assisting or sub-serving the arbitration process. It would also be useful to compare the legal research, analysis and arbitration result with that of the AI. ${ }^{61}$

Lastly, there is a prediction of arbitration result. Securing sufficient data related to arbitration is essential in AI-based predictions. It is not easy to secure data in the majority of international arbitrations. Especially, in the case of international commercial arbitration, arbitration rulings are not even published. On the other hand, many unredacted awards can be found in arbitrations between investors and nations at International Center for Settlement of Investment Dispute ("ICSID"), Society of Maritime Arbitrators ("SMA") and Court of Arbitration for Sport ("CAS"). ${ }^{62}$

With the growing need for the information included in the arbitration awards, a few organizations started to develop database, providing information related to

56 M. Hutson, Artificial Intelligence Prevails at Predicting Supreme Court Decisions, Scr. (News), May 2, 2017, available at https://www.sciencemag.org/news/2017/05/artificial-intelligence-prevails-predicting-supreme-court-decisions (last visited on May 2, 2019).

57 UNCITRAL Model Law on International Commercial Arbitration 2006, art. 7.

58 Convention on the Recognition and Enforcement of Foreign Arbitral Awards 1958 (New York Convention), art. V.

59 New York Convention, art. II(2).

60 J. Angwin, et al., Machine Bias, ProPuBlica, May 23, 2016, available at https://www.propublica.org/article/machinebias-risk-assessments-in-criminal-sentencing (last visited on May 23, 2016), See also A. Caliskan, et al., Semantics Derived Automatically from Language Corpora Contain Human-Like Biases, 356 Scr. 183-6 (2017).

61 Just like "ROSS" an Artificial Intelligence lawyer specializing in the Bankruptcy Law, all the analysis required for the final arbitration decision can be processed more efficiently.

62 K. Paisle \& E. Sussma, Artificial Intelligence Challenges and Opportunities for International Arbitration, 11 NYSBA New York Dispute Resolution Lawyer 35-40 (2018). 
arbitration. ${ }^{63}$ Representative database includes Arbitrator Intelligence, ${ }^{64}$ Dispute Resolution Data ${ }^{65}$ and Global Arbitration Review Arbitrator Research Tool ("GAR ART"). ${ }^{66}$ Although the database above help understand deeply the arbitration process, currently, analysis using AI is difficult in various aspects due to hurdle in acquiring full unredacted awards and analyzing the principle in relation to arbitration.

\section{B. Trial Prediction}

Trial Prediction ${ }^{67}$ refers to the technology of predicting the result of trials using computer algorithms and was introduced to the world with the nickname, AI Judge. ${ }^{68}$ Trial prediction relies on Machine Learning more than the conventional Expert System. In the US, actually, researches on trial prediction using AI have taken place from a long time ago. However, unlike domestic law, international law does not have a single hierarchical normative system but covers comprehensive fields horizontally. So it would not be easy to predict a trial. Even if international law is restricted to a particular field, it would be challenging to apply Machine Learning due to the lack of related precedents or legal data.

\section{Al and Trial prediction}

A leading study on trial prediction is related to predicting the result of the US Supreme Court's trial. The AI used for trial prediction is a conventional Machine Learning like a decision tree. ${ }^{69}$ In 2004, Andrew Martin and his colleague researchers adopted the decision tree technique to predict the result of the US Supreme Court

$63 I d$.

64 It will make available responses to detailed surveys to be completed by arbitration users who will report on their experiences with specific arbitrators. Arbitrator Intelligence has also collected almost 1,400 arbitral awards from jurisdictions around the world, which it intends to make available in some form.

65 It collects arbitration-related data from critical sources including most of the major international arbitration institutions.

66 It provides information about individual arbitrators which includes individual arbitrator's own responses as to their procedural preferences and practices as well as providing names of counsel who have appeared before the arbitrator and arbitrators with whom they have sat on an arbitration panel.

67 Trial Prediction or Predictive Trial refers to the set of efforts to predict a result of trial in advance which the author of this paper coined the terminology.

68 J. Vincent, AI Program Able to Predict Human Rights Trials with 79 Percent Accuracy, Verge, Oct. 24, 2016, available at https://www.theverge.com/2016/10/24/13379466/ai-judge-european-human-rights-court-prediction (last visited on May 13, 2019). See also N. Aletras, et al., Predicting Judicial Decisions of the European Court of Human Rights: A Natural Language Processing Perspective, 2 PeErJ Computer Scr. e93, 1-19 (2016).

69 Based on a few characteristics (input value, independent variable), this technique analyzes the pattern existing between the label (response value, dependent variable) value and identifies a combination of predictable rules. It is similar to Twenty Questions as it poses questions and narrows down the subject. 
cases. ${ }^{70}$ The justices and legal experts at the time were extremely skeptical about applying the technology to law. The research team, however, hosted a prediction contest (competition) and compared the predictions of legal experts and those of the algorithm. The result was a crushing defeat for the legal experts. The prediction of the legal experts stayed at 59 percent, while the result of the algorithm showed 75 percent prediction accuracy. ${ }^{71}$ Since then, the study of trial prediction on the US Supreme Court advanced further thanks to the efforts of Daniel Katz. In 2014, Katz developed an algorithm that could predict approximately 70 percent of the US Supreme Court cases through a project conducted by Michigan State University. ${ }^{72}$ In 2017, Katz team created a generalized methodology without a model specialized to individual Supreme Court Justice. ${ }^{73}$ Katz applied a random forest algorithm which is a Machine Learning technique that is more advanced than the initial decision tree. All the Supreme Court's precedents between 1816 and 2015 were analyzed as learning data. The study by Andrew Martin and Daniel Katz demonstrates clearly that Machine Learning is effective in trial prediction. ${ }^{74}$

A recent notable point is the study of trial prediction on the European Court of Human Rights ("ECHR"). In 2016, a joint research team comprised of University College London, the University of Sheffield and Pennsylvania State University developed an algorithm that predicts the ECHR trials. ${ }^{75}$ The performance showed approximately 79 percent conformity rate with the ruling of the court above, reaching the same conclusion in 4 out of 5 cases proceeded by the ECHR. ${ }^{76}$ The joint research team used Machine Learning to learn the relevant data on ruling (584 cases) in relation to Articles 3 (Prohibition of torture and inhuman or degrading treatment and punishment), Article 6 (Right to a fair trial) and Article 8 (Right to respect for private and family life) of the European Convention for Human Rights. As for the detailed algorithm, it was an algorithm called Support Vector Machine ("SVM") and not the existing decision tree. ${ }^{77}$ This study is significant in that it fully used the actual

71 Id.

72 PREPRINT ARXIV:1407.6333 (2014).

73 12 Plos ONE: e0174698, 1-18 (2017), available at https://www.researchgate.net/publication/311586220 A General Approach_for_Predicting_the_Behavior_of_the_Supreme_Court_of the_United_States (last visited on May 30, 2019).

76 Id.

77 C. Cortes \& V. Vapnik, Support-Vector Networks, 20 MachINE LeARnING 273-97 (1995).

A. Martin, et al., Competing Approaches to Predicting Supreme Court Decision Making, 2 PeRSP. PoL'y 761-7 (2004). d.

D. Martin Katz et al., Predicting the Behavior of the Supreme Court of the United States: A General Approach, ARXIV

This sentence synthesizes the findings from the aforementioned research articles.

Aletras, et al., supra note 68 , at 20. 
court materials instead of the subjective characteristics of the judge based on natural language processing.

\section{The possibility of Trial Prediction in International law}

Trial prediction shown above was possible due to explicit norms and sufficient data. However, the norms of international law are rather abstract dealing with various areas. Also in international law, many treaties can be interpreted vaguely under the political and cultural influence. Disputes between countries tend to be resolved amicably and secretly by a strong tradition in international customs. Therefore, international trials and authoritative rulings are not universal.

There are specialized international law fields such as the law of World Trade Organization ("WTO") and international criminal law. However relevant rulings are still insufficient. According to the WTO, 529 disputes are recorded as of September 8, 2017. According to International Court of Justice ("ICJ") records, there are 174 judicial precedents as of August 1, 2018 and the Former Yugoslavia War Tribunal have prosecuted 161 people and ruled approximately 100 verdicts. $^{78}$

The data is too limited for learning international law related judicial precedents using machine learning. Therefore, predicting trial results using machine learning in international related issues is not an easy task. Recently, however, machine learning techniques using only a small amount of data are appearing continuously. For example, one-shot learning and transfer learning are useful. One-shot learning refers to the field of Meta-Learning (learning how to learn) where a model is required to quickly learn a new task from one or a very few numbers of training data (hence the name). Transfer learning is a machine learning method that focuses on storing knowledge gained while solving one problem and transferring it to a different but related problem (hence the name). Transfer learning is useful in the case of insufficient data for a new domain. ${ }^{79}$ If the method of the ECHR is used in unique international law fields such as the WTO, trial prediction is not necessarily impossible.

\section{International Law and Machine Translation}

The field that needs AI desperately and realistically in international legal issues

78 WTO, Dispute Settlement, available at https://www.wto.org/english/tratop_e/dispu_e/dispu_e.htm. See also International Criminal Tribunal for the former Yugoslavia (ICTY), Infographic: ICTY Facts \& Figures, available at http:/www.icty.org/en/content/infographic-icty-facts-figures; ICTY Judgment List, available at http:/www.icty.org/ en/cases/judgement-list (all last visited on Apr. 16, 2019).

79 S. Pan \& Qiang Yang, A Survey on Transfer Learning, 22 Ieee Transactions on Knowledge and Data Engineering 1345-59 (2009). 
would be translation. English materials related to international law require translation work into the languages of each country. Translation is done in all international law materials. For instance, there would be treaties, international precedent materials, international conference materials and others. Unlike other foreign language translations, critical legal problems would occur in the event of mistranslation in the field of international law. If the legal norms contained in the original text are not properly translated in the translation process, sanctions may be imposed on the recipient regardless of the intent of the sender. For this nature of legal texts, legal translations have the potential to cause a great deal of damage and loss to translators than any other translation. Therefore, a lot of workforce and expenses are required in order to reduce mistranslations. In international law, one could actively utilize Machine Translation ("MT") technology using AI to resolve such issues.

MT refers to automated work of translating the source text into target text by using the computer. Studies on MT had already started in the initial stage of AI. ${ }^{81} \mathrm{MT}$ had various problems such as the quality of translation. However, both the EU and the US used translation based on MT system from a long time ago. The place that urgently needed MT was international institutions such as the UN and the European Commission. ${ }^{82}$ Even now, many international institutes use automated MT system. Recently, Deep Learning began to be applied to MT and its performance enhanced rapidly. Therefore, MT will ultimately play crucial role in bridging the international society. ${ }^{83}$

\section{Flow of MT}

MT is largely classified into Rule-Based MT ("RBMT") and Statistical MT ("SMT"). RBMT is a translation method of regularizing the grammar which was mostly used previously. As it translates based on grammar, it is highly accurate and professional per field. However, sentences that deviate from grammatical rule is highly likely to

81 W. Weaver, Translation, 14 Machine Translation of Languages (1955). See also W. Weaver, Letter to Norbert Wiener, Mar. 4, 1947, available at http://www.mt-archive.info/Weaver-1947-original.pdf (last visited on May 31, 2019).

82 EC Joint Commission commenced the development of auto language translation system called EUROTRA in 1976 to reduce the colossal work and labor cost arising from the different languages, executing translation in 81 directions among 9 languages. At first, it was for 7 EC member countries like UK, France, Germany, Italy, Denmark, Netherlands and Greece but later on, Portugal and Spain were added so the development of translation system for 9 languages began in 1982 and was completed in 1993.

83 D. Bahdanau, et al., Neural Machine Translation by Jointly Learning to Align and Translate, ARXIV PREPRINT ARXIV:1409.0473 (2014). 
be mistranslated. ${ }^{84}$

SMT builds the rule-based models on an immense amount of Bilingual Corpus by translating into word and phrase format respectively and combining them. ${ }^{85}$ The existing Google and others used a method called SMT or Phrase-based MT ("PBMT"). ${ }^{86}$

Recently, SMT is evolving into Neural MT ("NMT") method. Researchers attempted to apply Deep Learning to improve the problems of the existing translation method. In 2016, Google unveiled the Deep Learning-Based NMT for the first time in the world. ${ }^{87}$ Neural MT brought innovation to MT.

\section{Neutral MT}

The representative neural network that appears in NMT is Recurrent Neural Network ("RNN"). ${ }^{88}$ RNN is one of deep learning algorithms which processes sequence data with time or order. ${ }^{89}$ Unlike general neural networks, RNN can use internal state (memory) to process sequences of inputs. For their internal memory, RNN is able to remember important things about the input it received, which enables it to be very precise in predicting what's coming next. This is the reason why RNN is the preferred algorithm for sequential data like time series, speech, text, financial data, etc. ${ }^{90} \mathrm{RNN}$ is able to create outputs in diverse forms by receiving the input. ${ }^{91}$ The basic structure of NMT is a connection of two RNN modules as seen below.

W. Hutchins, Machine Translation: A Brief History, in Concise History of the Language Sciences (E. Koerner \& R. Asher eds., 1995).

85 Id.

86 The principle of such method is simple. First, various meanings of a word or phrase are saved. It creates the so-called translation dictionary. Next, if the user inserts a sentence, it is divided into words or phrases and proposes the translation result that is judged to be closest to the original meaning.

87 Yonghui Wu, et al., Google's Neural Machine Translation System: Bridging the Gap Between Human and Machine Translation, ARXIV PREPRINT ARXIV:1609.08144 (2016).

88 Id. at 25. See also Junyoung Chung, et al., Empirical Evaluation of Gated Recurrent Neural Networks on Sequence Modeling, ARXIV PREPRINT ARXIV:1412.3555 (2014); T. Mikolov, et al., Recurrent Neural Network Based Language Model (2010). Recently, LSTM (Long Short-Term Memory) which complements the disadvantages of early RNN is widely used. W. Zaremba, et al., Recurrent Neural Network Regularization, ARXIV PREPRINT ARXIV:1409.2329 (2014).

91 In particular, if the output has a sequence like the input data, it is called Sequence-to-Sequence (seq2seq) models. See generally I. Sutskever, et al., Sequence to Sequence Learning with Neural Networks (2014); Kyunghyun Cho, et al., Learning phrase representations using RNN encoder-decoder for statistical machine translation, ARXIV PREPRINT ARXIV:1406.1078 (2014). Seq2seq models have enjoyed great success in a variety of tasks such as machine translation (NMT), speech recognition, and text summarization. 
Figure 1: Basic Structure of $\mathrm{NMT}^{92}$

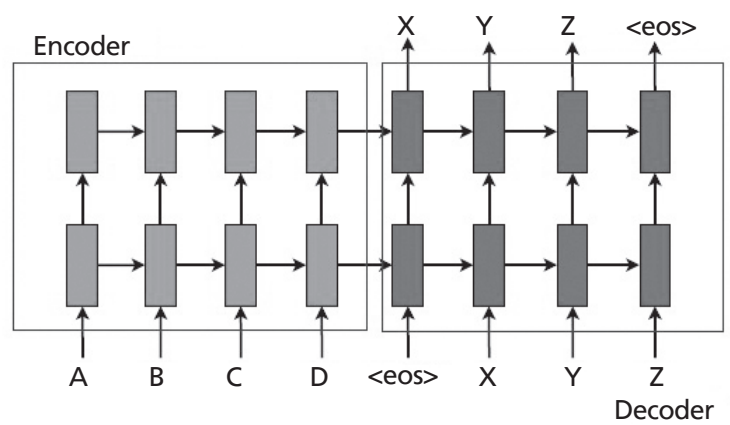

One is called an encoder and the other one is called a decoder. An encoder converts a source sentence into a 'meaning' vector which is passed through a decoder to produce a translation. You will feed an English sentence to encoder and feed the output state of encoder into the decoder. Then, the decoder will generate a French sentence.

As it can be seen from the figure below, the sentence, "Je suis etudiant" can be produced from the word, "I am a student." Since the appearance of NMT, the performance of MT has enhanced remarkably. Recently, attention model which focuses on important part of input sentence in the decoding process was introduced and MT continues to evolve.

Figure 2: Modified Architecture of the Encoder-Decoder in Translation ${ }^{93}$

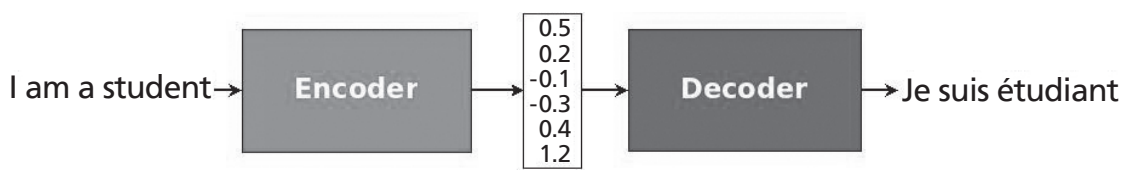

\section{International Law and Translation Problems}

In international law, translation problems are always bound to occur in countries that do not use English as the native language or the official language. ${ }^{94}$ In particular, translation plays an extremely important role in treaty-making from the signing

4 Man-ho Bae \& So-min Bae, Translation Strategies for International Legal Documents: Focusing on the "United Nations Convention on the Rights of Persons with Disabilities," 12 Interpreting and Translation Studies 161-81 (2009). < available only in Korean> 
process to the stage where the final rules are specified. Mistranslation causes critical legal problems between countries.

The Treaty of Waitangi is the most famous case of treaty mistranslation. The Treaty of Waitangi is a treaty signed on February 6, 1840 between representatives of the UK and Maori in order to stop armed conflicts in the Island of Waitangi, a northern island in New Zealand. The translation from English to Maori caused legal problems in this treaty. For example, as there was no word for sovereignty in Maori, 'kawanatanga,' a protolanguage of the Maori tribe was used. However, 'kawana' in 'kawanatanga' is just a word spelling out the English word 'governor' by pronunciation. When translated into English, it means governance rather than sovereignty. Due to these reasons, the Maori party claimed "All land belongs to us," while the British apprehended that "New Zealand is a colony of Great Britain." This mistranslation is causing severe controversy regarding the rights of Maori even to this day. ${ }^{95}$

The Waitangi Treaty case is just the tip of the iceberg. These types of errors are frequently occurring. In Korea, there are many mistranslations in treaties. Mistranslations have been found in the Korean version of the Comprehensive Economic Partnership Agreement ("CEPA") between South Korea and India. Such mistranslations have also occurred in the Korean version of the Korea-EU FTA. In particular, the mistranslation in the Korean version of the Korea-US FTA led to legal issues. ${ }^{96}$ There was a verdict demanding the errata to be disclosed as follows: "If the amendment details caused by mistranslation in the agreement are announced objectively and transparently, conditions for social consensus regarding the Korea-US FTA could be created, leading to high public value." 97

Mistranslation of treaties is a risk factor in terms of international law that all countries potentially carry. The field of international law which concerns various countries with different languages essentially carry these risks. Therefore, machine translation based on Deep Learning can be considered as a way to reduce these risks.

\section{Automated Legal Translation Collaboration System}

AI will probably be used in translating international law documents automatically

96 See Huge Number of Translation Errors Found in Korea-EU FTA, CHosunilbo DAILY, Apr. 5, 2011, available at http:// english.chosun.com/site/data/html_dir/2011/04/05/2011040501248.html (last visited on May 13, 2019).

97 The Korean version of Korea-US FTA and Korea-EU FTA are equivalent to the English version. As an equivalent text, there was discordance between the English and Korean version. This is, in fact, not mistranslation but is discordance in legal effect. Therefore, the translation of treaty has to be approached extremely carefully as it is not just a simple translation. 
and in interpreting simultaneously in international trials and arbitration. However, AI only acts as an assistant to human beings at the moment, as opposed to translating or interpreting completely on behalf of humans. Neural network translation needs vast learning data in the translation field. However, as international law does not have enough data, it is difficult to expect outstanding translation performance. Furthermore, as accurate translation is crucial in international law unlike other fields, the accuracy of machine translation needs to be further assured. A model in which human beings and machines collaborates is ideal in reality. The effect of this collaboration model would enhance the quality of translation by using $\mathrm{AI}$ as a tool for systemizing legal translation.

Legal translation consists of three stages in general. In Stage 1, a professional translator carries out the translation and in Stage 2, the translation is proofread by a native speaker. In Stage 3, the translation is examined again by lawyers. Mistranslation is prevented and translation quality can be enhanced by repeating these stages. However, the problem in each stage is that proofreading has to be made in the upper stage, but reviewing legal issues and translating are different tasks. Thus, it is difficult to catch all the mistranslations.

As such, it is extremely important to systemize the translation process by making full use of the computer. Computer-assisted Translation (“CAT") is utilized frequently in general translation. CAT includes materials and references with regards to relevant fields, glossary research and analysis preparation, translation, editing, formatting and proofreading. ${ }^{98}$ Revision procedure by a third party is required depending on the type of translation. Proofreading is not only required in the editing process, but is also required in the final stage.

Proofreading by a legal specialist is absolutely necessary for legal translation. In addition, it is also important to establish a system which is capable of objectifying the subjectivity of legal specialists when selecting the terminology. AI can intervene in all processes. The most straightforward way is combining MT system with CAT. Thus, the initial translation begins with MT and its result is proofread by a translation specialist. In the intermediate stage, the legal specialist carries out the proofreading and then the translation specialist reviews it again. All these processes must take place in a collaboration method through the computer system. Finally, the legal specialist carries out the final proofreading which requires the collaboration between international and domestic law specialists. The editing process and translated words are all saved in the database. This data will be utilized again as the learning data for

98 S. Barrachina, et al., Statistical Approaches to Computer-Assisted Translation, 35 Computational Linguistics 3-28 (2009). 
AI. Collaborated CAT combined with AI is expected to maximize the efficiency of legal translation.

\section{Objectification of Legal Translation Evaluation}

Legal translation is the work of replacing the words and phrases of the original legal system to the corresponding expression with "fidelity to the source text("ST") being the first consideration." 99 Therefore, the standard of translation quality is achieving equivalence. ${ }^{100}$ This can be similar to the source-oriented approach which is a method of evaluating the quality of target text ("TT") depending on the extent of deviation from the equivalence of ST. ${ }^{101}$ So far, the majority of legal translation evaluation that has taken place in Korea can be classified as having used "the source-oriented evaluation method" which evaluates mistranslation based on the achievement of formal equivalence. For example, the discussion concerning legal translation quality evaluation that surfaced during the Korea-US FTA mistranslation event shows that equivalent attainment at the lexical level centered on legal terminology is used as the main criteria. $^{102}$

However, the majority of legal translation that is done as part of the public translation initiative in Korea is not considered as an authoritative translation. In other words, the translated material is considered only as an official translation which provides information or is used as a reference about the law. Therefore, evaluation centered on the receiver's understanding is also important. Legal translation, just like general translation, requires "the Receiver-Oriented evaluation method" which demands the text to be the basic unit instead of words. ${ }^{103}$

AI or computer can be used not only for doing the actual translation work, but for evaluating the quality of existing translated materials. Bilingual Evaluation Understudy ("BLEU") is a technique that measures the quality of machine translation objectively. BLEU was developed by IBM in 2002. ${ }^{104}$ As one of the quantitative

99 S. Sarcevic, New Approach to Legal Translation 229 (1st ed. 1997).

100 Bae \& Bae, supra note 94, at 28.

101 J. Williams \& A. Chesterman, The Map: A Beginner's Guide to Doing Research in Translation Studies 48-58 (2014).

102 In 2011, the Ministry of Foreign Affairs and Trade revealed that as a result of inspecting the Korean copy of the KoreaEU FTA, there were more than 200 mistranslations. 296 errors in total, such as 166 cases of mistranslation, 9 cases of orthography, 25 cases of inconsistency, 13 errors in the indication of Proper Noun, were discovered, amended and the revised agreement was disclosed.

103 Jeongju Yoo, Assessing Textual Fit of Translated Statutes: A Model for Legal Translation Quality Assessment, 19 INTERPRETATION AND TRANSLATION 101-30 (2017).

104 K. Papineni, et al., BLEU: A Method for Automatic Evaluation of Machine Translation, in Proc. The 40Th AnNuAL MeEting on Association for Computational Linguistics 311-8 (2002). 
indexes for measuring the translation quality, BLEU measures the translation quality by determining how many words are in common between the translated sentence and the reference pool that has been selected by humans. BLEU method can be applied to Receiver-Oriented evaluation. However, a more precise evaluation system is required for treaty translation or production of authoritative translation. For example, a hybrid evaluation system which reflects both lexical equivalence and legal semantic equivalence can be used. An automated evaluation collaboration system similar to the automated translation collaboration system is an example as well. As a result, it is essential to establish an objective evaluation system with regards to legal translation for international law. Computers or AI must also be utilized actively for detecting translation errors.

\section{Conclusion}

Globalization is an inevitable flow of contemporary human society. In the globalization process, various disputes occur in nations and companies as they become entangled beyond boundaries. In such disputes, international legal issues lay hidden fundamentally. In particular, international economic law is gaining a more important position gradually due to the expansion of transnational trade and investment. Disputes between countries are generally mediated by international law rather than international economics law. In international law, treaties and customary international law are important. Problems in international laws have been resolved based on conventional methods. Translating, interpreting and applying treaties as well as customary international law are works that are all done by human.

The modern AI automates legal work, analyzes documents and predicts trials. In the era of legal AI and Legal Tech, international law can benefit from the help of cutting-edge technology, as well. The translation of treaty differs from the translation of general documents. Mistranslations lead to serious legal and political disputes. Therefore, Deep Learning-based MT and Collaboration AI System with humans will play an influential role in international law. Besides, AI would be applied to the quality evaluation with regards to existing translated materials and the standardization work will become an international legal issue.

We can think about applying ODR and AI in the field of international arbitration. It is not difficult to use conventional expert system in international arbitration. However, replacing an arbitrator with AI is technically not easy. In the case of 
international disputes, particularly, the materials to be analyzed are immense so that $\mathrm{AI}$ is not expected to make decisions. However, we can imagine AI helping the appointment of an arbitrator.

In the realm of law, predicting the result of trials is particularly important. AI that can predict trials by learning the precedent of the ECHR has appeared. Together, we can think about a system that can predict trials related to international law. However, the trial materials or data of the ICJ or the WTO are so poor that creating a Machine Learning-based Prediction System would not be very optimistic in the near future. Even in the case of international arbitration, it is difficult to secure the related materials. Therefore, to create an AI that can predict the arbitration result is difficult. However, new machine learning methods such as one-shot learning and transfer learning can be useful in the case of insufficient data. In the future, we could expect the advent of prediction algorithm in any degree if we prepare a standardized procedure and prepare data for learning.

International law is different from domestic law. International law does not have the rules centered on massive law books like domestic law. Furthermore, as the trial cases and precedents are not diverse, it is challenging to presume an analysis pattern. In practice, however, $\mathrm{AI}$ is innovating the legal ecology fundamentally. International law would eventually accept such changes. In the future, international law will be more important. When international law is closely affiliated with AI, it would exhibit greater force. 